\title{
Understanding Singaporean medical students' stress and coping
}

\author{
Li $\underline{W u}^{1}$, PhD, Julia Farquhar ${ }^{2}$, Jackie $\underline{M a}^{3}$, Arpana $R \underline{\text { Vidyarthit }}^{4,5}, \mathrm{MD}$
}

\begin{abstract}
Medical school is intrinsically stressful, and high levels of stress have untoward effects. Although surveys have revealed some sources of stress among medical students, little is known about the qualitative aspects of these stressors and their associated coping behaviours, particularly among medical students in Singapore. Our exploratory pilot study found that relationship issues and examinations were the major sources of stress for medical students. The respondents described multiple context-sensitive coping styles, as well as reported 'avoidance' or 'wishful thinking' coping strategies as ineffective. Their stress-and-coping process suggests the influence of Asian culture and medical school culture. Our findings thus indicate the need for further research, potentially using new methodologies such as the critical incident analysis technique, and thoughtful consideration of culture when implementing programmes in Singapore medical schools to improve the students' stress-and-coping responses.
\end{abstract}

Keywords: coping, medical students, stress

\section{INTRODUCTION}

Medical students experience significant stress during medical school, which can lead to depression, burnout and anxiety. ${ }^{(1)}$ This negative well-being, which is more severe than among their nonmedical peers, ${ }^{(2)}$ influences their quality of life and patient care outcomes. ${ }^{(3,4)}$ Understanding the nuances and details of medical student stress is therefore paramount, as this may have long-term and far-reaching impact.

Current understanding of medical student stress is derived mostly from survey studies. These reveal common stressors, including heavy study load, concerns about assessment, lack of leisure time and transition from pre-clinical to clinical training. ${ }^{(5,6)}$ Although these studies inform our understanding of medical students' stress, they are limited in that they do not explore the intrinsic connections between stress and its related coping strategy, nor shed light on the experiences of students in Singapore.

Lazarus and Folkman described this connection as a transactional process, during which individuals make situational appraisals of the possibility for control in their stressful encounters and adopt unique coping strategies accordingly. ${ }^{(7)}$ These coping strategies may be problem-focused or emotion-focused, as described in the transactional theory of stress and coping. ${ }^{(8)}$ Problem-focused coping involves actively changing the stressful situation and predominates when the situation is viewed as controllable. Emotion-focused coping involves regulating stressful emotions without changing the situation and is favoured when the situation has to be accepted. Studies on stress coping strategies in medical students show that they employ both styles, but to date, none have linked the stressful situation to the type of coping strategy utilised and few have provided the nuances of their experiences, especially those of Asian medical students, and specifically those from Singapore. ${ }^{(5)}$
Critical incident analysis ( $\mathrm{ClA})$ is an effective exploratory tool that involves asking respondents to systematically identify events that are critical for some experiences. The CIA technique was first developed by Flanagan in 1954 to identify the critical requirement for job success, and it was subsequently used in many fields. ${ }^{(9)}$ When applied to the stress-and-coping process, the $\mathrm{CIA}$ technique asks individuals to describe their stressors and coping behaviours in relation to the stressful events, and the outcomes of these behaviours. ${ }^{(10)}$ This approach ensures that the specific stressors and coping behaviours are salient to the respondent. Moreover, previous studies using CIA have supported the theoretical emphasis on environmental characteristics in relation to the choice of coping options, i.e. coping responses are likely to be related to differences in the stressful contexts. ${ }^{(10-12)}$ There are currently no published reports of this technique being used with medical students.

In order to gain a preliminary understanding of how medical students in Singapore experience stress and its related coping strategies, we utilised the CIA technique with a pilot group of medical students from Duke-NUS Medical School (Duke-NUS), Singapore. We aimed to identify the types of stressful situations that these medical students experience, describe the category of coping strategies they employ with each type of stressor, and explore the effectiveness of their coping strategies. We hypothesised that this methodology applied in Singapore may reveal previously unrecognised themes, which could be important in creating programmes to improve the effectiveness of Singapore medical students' stress-and-coping responses.

\section{EVALUATION OF THE ISSUE}

We asked Duke-NUS students who were recruited to participate in a larger study exploring stress, coping, resilience and burnout ${ }^{(13)}$ 
to anonymously complete a survey designed using the CIA technique. The CIA survey queried three elements in the stressand-coping process: (1) the stressful incident; (2) the student's coping response(s) to that particular stressful episode; and (3) a numeric rating ( 1 = not effective, 10 = very effective; a cutoff mean value of 5.0 was defined as 'effective') of the effectiveness of their coping behaviour(s). ${ }^{(10)}$ We asked our participants to describe up to four incidents that occurred during the past school year.

We coded the data using standard qualitative content analysis methodology. ${ }^{(14)}$ Three coders (LW, AV, JM) independently generated initial codes of the stressful incident and the coping behaviours reported, after which the codes were refined and applied to all transcripts, and discrepancies were resolved through a consensus process. Thereafter, LW and JM coded all the data independently with the final coding scheme. Codes were analysed for patterns and meaning, and delineated into categories and subcategories.

\section{STUDY FINDINGS}

A total of 32 students (16 female, 16 male) across the four years completed the CIA survey. ${ }^{(10)}$ Of these, 15 (47\%) were Singaporean, 14 (44\%) were non-Singaporean Asians, and 3 (9\%) were non-Asian. The mean age of the sample was 26 (range 23-31) years.

\section{Stressful situations}

The participants reported 62 stressful incidents (ranging from 1-4 incidents per respondent, with a mean of 1.97 and median of 2; Table I). Relationship issues, in several dimensions, were the most frequently mentioned source of stress. Examinations were another leading source of stress; this included the stress experienced while preparing for major or minor examinations, and when 'failing' or 'not doing well' in examinations. Three other categories were less common but nonetheless articulated by our respondents.

\section{Situational coping behaviours of relationship and assessment stressors}

Each participant reported 1-3 coping responses for each stressful incident, which yielded a total of 69 coping responses. The broad categories of problem-focused and emotion-focused coping responses were further delineated into subcategories that emerged from the data. Problem-focused coping included planning and problem-solving (41\% of the coping responses) and seeking instrumental social support (17\%). Emotion-focused coping included positive reappraisal (13\%), acceptance $(10 \%)$, avoidance or wishful thinking (10\%), venting emotions (6\%) and relaxation (3\%).

Overall, the respondents more frequently reported problemfocused coping $(57 \%)$ than emotion-focused coping $(43 \%)$ in dealing with relationship stress. However, their coping behaviours varied depending on the status of the other party involved in the relationship. When dealing with relationship issues with family members and clinical supervisors, they mainly used planning and problem-solving (e.g. 'apologising and talking it out') and seeking instrumental social support to improve the relationship (e.g. 'talking to my other mentor to see what can be done'). In contrast, emotion-focused coping strategies predominated in dealing with peer-to-peer challenges, including venting emotions (e.g. 'confiding in my friends') and avoidance or wishful thinking (e.g. 'it's been about a month and we currently don't speak'). Overall, the participants reported almost the same amount of problem-focused and emotion-focused coping both before and after examinations. During examination preparation, they mainly used problem-solving ('working hard') and positive reappraisal ('told myself that my classmates were unlikely to have done very differently to me'). They coped with stress related to unsatisfactory examination results in a similar pattern.

\section{Coping effectiveness}

We calculated the mean effectiveness of each coping category across all stressful categories and subcategories. Planning and problem-solving $(6.7 \pm 0.86)$, seeking instrumental social support $(7.8 \pm 1.07)$, positive reappraisal $(7.4 \pm 0.82)$, acceptance $(6.5 \pm$ $0.84)$, venting emotions $(6.8 \pm 1.23)$ and relaxation $(7.7 \pm 0.75)$ were regarded as effective. Avoidance or wishful thinking was reported as ineffective $(4.2 \pm 1.03)$.

\section{UNDERSTANDING AND IMPLICATIONS}

This pilot study investigated medical student stressors, their related coping responses and associated effectiveness using the $\mathrm{CIA}$ technique. We found that relationship issues and examinations were the most prevalent sources of stress. In addition, students employed different styles of coping across various stressful situations and described most of them as effective, with the exception of avoidance and wishful thinking.

Our findings hint at the influence of culture in stress and coping; however, given the nature of our pilot study, the linearity of this relationship was not proven. We found that students experienced examination stress, which affirms prior data, ${ }^{(5)}$ but our respondents also described stress arising from relationships, which has not been previously reported. This finding is notable, as medical students are likely to experience a variety of relationship challenges given their age and position in the medical hierarchy. Conflicts with supervisors, such as verbal abuse as described by our students, is a major issue in medical education, ${ }^{(15)}$ and the issue of heavy workloads negatively affecting family relationships is also prevalent. ${ }^{(16)}$ These relationship stresses may be especially germane to Asian students because the Asian culture values the ability to maintain harmonious relationships with group members. ${ }^{(17)}$ Our findings lay a foundation for further understanding the extent and nature of relationship-related stress as experienced by medical students.

In all stressor categories, our students utilised different coping strategies based on the situation. This is consistent with the transactional theory of stress and coping, which states that coping is context-dependent and related to the cognitive appraisal of the event. Our students predominantly adopted problem-focused coping in the face of stress that could be alleviated, such as having a cold. In contrast, they reported more emotion-focused coping in dealing with issues for which they could not control the situation, 
Table I. Example quotes of coping responses that deal with each category of stressor.

\begin{tabular}{|c|c|c|}
\hline \multirow[t]{2}{*}{ Stressor } & \multicolumn{2}{|c|}{ Situational coping strategy } \\
\hline & Problem-focused coping & Emotion-focused coping \\
\hline \multicolumn{3}{|l|}{ Relationship } \\
\hline $\begin{array}{l}\text { Peer } \\
\text { "I did not want to be 'partners' with the person I am } \\
\text { 'partnered' with for clerkship rotations in Year 2." } \\
\text { "Dealing with teammates. I feel left out on the team." }\end{array}$ & $\begin{array}{l}\text { Problem solving } \\
\text { "Spoke to the person, tried to reason with } \\
\text { the person, tried to implement strategies to } \\
\text { improve teamwork etc." }\end{array}$ & $\begin{array}{l}\text { Venting emotions } \\
\text { "Speaking to my significant } \\
\text { other to ventilate." } \\
\text { Avoidance } \\
\text { "Treat them as nicely as I can, } \\
\text { hope that it goes away/avoid } \\
\text { otherwise." } \\
\frac{\text { Relinquished coping }}{\text { "Doing nothing." }}\end{array}$ \\
\hline $\begin{array}{l}\text { Consultant/supervisor } \\
\text { "[The] Consultant was very dogmatic and harsh } \\
\text { during ward rounds." }\end{array}$ & $\begin{array}{l}\text { Problem solving } \\
\text { "Take it humbly, look at own faults, seek to } \\
\text { improve." } \\
\text { Seeking instrumental social support } \\
\text { "Talk to my other mentor and see what can } \\
\text { be done." }\end{array}$ & $\begin{array}{l}\text { Acceptance } \\
\text { "Take a deep breath and just let } \\
\text { it go." }\end{array}$ \\
\hline $\begin{array}{l}\text { Family } \\
\text { "[My] family members [were] not happy with me } \\
\text { studying over the holidays." }\end{array}$ & $\begin{array}{l}\text { Problem solving } \\
\text { "Talking to family members, writing letters } \\
\text { to family." } \\
\text { "Talked the problems out." }\end{array}$ & \\
\hline $\begin{array}{l}\text { Romantic } \\
\text { "Relationship breakup during medical school." } \\
\text { "Having a fight with significant other." }\end{array}$ & $\frac{\text { Problem solving }}{\text { "Apologise and talk it out." }}$ & $\begin{array}{l}\text { Relaxation } \\
\text { "Went to travel alone during the } \\
\text { break." }\end{array}$ \\
\hline Assessment & & \\
\hline $\begin{array}{l}\text { Results } \\
\text { "Failing the first Objective Structural Clinical } \\
\text { Examinations (OSCE) is stressful." }\end{array}$ & $\frac{\text { Problem solving }}{\text { "Study harder." }}$ & $\begin{array}{l}\text { Positive reappraisal } \\
\text { "Tell myself that there are many } \\
\text { factors affecting the results; } \\
\text { I just need to be confident } \\
\text { and keep studying hard in the } \\
\text { future." } \\
\text { Wishful thinking } \\
\text { "Wish I could have prepared } \\
\text { myself before Normal Body } \\
\text { more, mentally and physically." }\end{array}$ \\
\hline Being overscheduled & & \\
\hline $\begin{array}{l}\text { Heavy coursework } \\
\text { "Given lots of reading materials that seem impossible } \\
\text { to finish reading." }\end{array}$ & $\begin{array}{l}\text { Problem solving } \\
\text { "Increase efficiency of study of assigned } \\
\text { material as a major consumer of time. } \\
\text { Reduction of time spent in bed." }\end{array}$ & 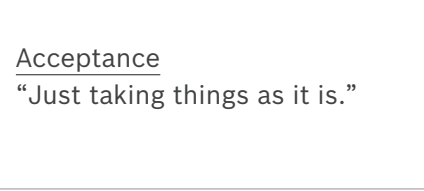 \\
\hline $\begin{array}{l}\text { Juggling between school vs. personal responsibility } \\
\text { "My USMLE Step } 1 \text { exam got postponed because the } \\
\text { exam centre couldn't load the test on the computer } \\
\text { on the day of the exam. I was to fly abroad for my } \\
\text { holiday the next week as well as submit all my } \\
\text { conference abstracts by then." }\end{array}$ & $\begin{array}{l}\text { Problem solving } \\
\text { Made a plan which was prioritised in the } \\
\text { following order: } \\
\text { 1) Waited an hour ( } 30 \text { mins }-1 \text { hr) for my } \\
\text { emotions to cool down } \\
\text { 2) Wrote down options (A), (B), and (C) I } \\
\text { had (e.g. taking the exam back home, } \\
\text { postponing, etc.) } \\
\text { 3) Discussed it calmly with my parents }\end{array}$ & $\begin{array}{l}\text { Acceptance } \\
\text { "Sleep more and just take things } \\
\text { as it is, day by day (coping). } \\
\text { Lower expectations, since I } \\
\text { cleared OSCE II." }\end{array}$ \\
\hline
\end{tabular}


Table I. (Contd...)

\begin{tabular}{|c|c|c|}
\hline \multirow[t]{2}{*}{ Stressor } & \multicolumn{2}{|c|}{ Situational coping strategy } \\
\hline & Problem-focused coping & Emotion-focused coping \\
\hline \multicolumn{3}{|l|}{ Illness } \\
\hline "Increased episodes of flu/colds." & $\begin{array}{l}\text { Problem solving } \\
\text { "Drinking water, sleeping earlier." } \\
\text { "Eating comfort food." }\end{array}$ & \\
\hline \multicolumn{3}{|l|}{ Disillusionment with medical school } \\
\hline $\begin{array}{l}\text { "Medical school as a whole. Not as meaningful as I } \\
\text { had believed. Many things feel irrelevant." }\end{array}$ & $\begin{array}{l}\text { Problem solving } \\
\text { "Volunteering with friends. Trying to find } \\
\text { meaning." }\end{array}$ & $\frac{\text { Relaxation }}{\text { "Doing weekly runs to destress." }}$ \\
\hline \multicolumn{3}{|l|}{ Acculturation } \\
\hline $\begin{array}{l}\text { "Adjusting to a new environment, a new country l've } \\
\text { never been to before, not having family as support." }\end{array}$ & $\begin{array}{l}\frac{\text { Problem solving }}{\text { "Tried to meet new people. Find interests. }} \\
\text { Make new friends." }\end{array}$ & \\
\hline
\end{tabular}

such as being overscheduled. They rated most of their coping responses as effective, with the exception of avoidance or wishful thinking. These findings, together with the identified common stressors, may inform students and medical educators of tactics to effectively manage the possible stressors in medical school.

Our findings also revealed the influence of culture on coping behaviours. Within relationship stress, our respondents used different types of coping mechanisms based on the status of the person within the hierarchy of the relationship. For example, they utilised 'apology' in the face of verbal abuse from clinical supervisors, and they used 'venting emotions' or 'avoidance' to cope with peer relationship problems. This may reflect the emphasis on hierarchical relationships and respect for authority in Asian societies, ${ }^{(17)}$ wherein subordinates (e.g. students in relation to supervisors) seldom use confrontation to deal with conflicts with authorities. In addition, our participants did not report drug or alcohol use as a coping mechanism, a finding that differs from studies of medical students in the United States. ${ }^{(18)}$ This could reflect the Singaporean culture where it is unusual for medical students to misuse substances due to strict drug laws. The culture of the school also influenced our participants' coping responses. For example, prior data showed that college students used more problem-focused coping in preparation for examinations and emotion-focused coping after receiving unsatisfactory examination results. ${ }^{(19)}$ Our students used both coping strategies equally before and after examinations. This may represent normalisation of the examination experience, because medical students in general, and specifically at our medical school, take multiple examinations as compared to their non-medical peers. This concept of culture influencing coping behaviours is relevant, as it can help us better understand the experiences of medical students; however, it has not been previously reported and thus warrants further research. ${ }^{(20)}$

Our pilot study has some limitations. Firstly, it consisted of a small convenience sample from a single site in Singapore, thereby limiting the generalisability or transferability of our findings. Secondly, although the present study has identified the main categories of stressors and linked strategies, the frequency is only hinted at. A follow-up survey on the study population is needed to determine the magnitude of these categories.

As this is the first investigation of situational coping conducted among medical students in Singapore, we believe that, despite the study's limitations, our preliminary findings (a) offer proof of concept regarding the potential use of the $\mathrm{CIA}$ tool in this population; (b) provide insights into Singapore medical students that have not been previously explored; and (c) lay a foundation for further research in this area. Our approach provides a configuration of the stress-and-coping relationship, which shows a more comprehensive picture than other coping strategy instruments. Future studies could explore this stress-andcoping process and its effectiveness with a larger sample size.

\section{EXPLORING IMPLICATIONS}

Stress is inevitable in medical school. Our findings suggest a need to further understand the role and impact of stress that is specific to medical students in Singapore, as they may differ from that of medical students elsewhere, as reflected in previously published data. ${ }^{(5,6)}$ Additionally, our findings suggest that thoughtful consideration of the culture to which the medical students are exposed is needed to better understand their experiences, as well as to create programmes to improve the effectiveness of their coping response. Current published stress reduction programmes do not take culture into account and, therefore, we should consider a localised approach that takes into account Singaporean and Asian culture when designing interventions. These are important first steps toward mitigating the negative effects of medical students' stress and in fostering resilient future doctors in Singapore.

\section{REFERENCES}

1. Firth-Cozens J, Greenhalgh J. Doctor's perceptions of the links between stress and lowered clinical care. Soc Sci Med 1997; 44:1017-22.

2. Rosenthal JM, Okie S. White coat, mood indigo--depression in medical school. N Engl J Med 2005; 353:1085-8.

3. Ishak W, Nikravesh R, Lederer S, et al. Burnout in medical students: a systematic review. Clin Teach 2013; 10:242-5.

4. West CP, Huschka MM, Novotny PJ, et al. Association of perceived medical errors with resident distress and empathy: a prospective longitudinal study. JAMA 2006; 296:1071-8.

5. Moffat KJ, McConnachie A, Ross S, Morrison JM. First year medical student 
stress and coping in a problem-based learning medical curriculum. Med Educ 2004; 38:482-91.

6. Radcliffe $\mathrm{C}$, Lester $\mathrm{H}$. Perceived stress during undergraduate medical training a qualitative study. Med Educ 2003; 37:32-8.

7. Lazarus RS, Folkman S. Stress, Appraisal, and Coping. New York: Springer 1984.

8. Folkman S, Lazarus RS, Dunkel-Schetter C, DeLongis A, Gruen RJ. Dynamics of a stressful encounter: cognitive appraisal, coping, and encounter outcomes. J Pers Soc Psychol 1986; 50:992-1003.

9. Flanagan JC. The critical incident technique. Psychol Bull 1954; 51:327-58.

10. O'Driscoll MP, Cooper CL. A critical incident analysis of stress-coping behaviours at work. Stress Med 1996; 12:123-8.

11. Newton TJ, Keenan A. Coping with work-related stress. Hum Relat 1985 38:107-26.

12. Wiersma UJ. A taxonomy of behavioral strategies coping with work-home role conflict. Hum Relat 1994; 47:221.

13. Farquhar J, Lie D, Chan A, Ow M, Vidyarthi A. Understanding medical students' experience with stress and its related constructs: a focus group study from
Singapore. Acad Psychiatry 2018; 42:48-57.

14. Downe-Wamboldt B. Content analysis: method, applications, and issues. Health Care Women Int 1992; 13:313-21.

15. Richman JA, Flaherty JA, Rospenda KM, Christensen ML. Mental health consequences and correlates of reported medical student abuse. JAMA 1992; 267:692-4.

16. Perrin K, Prasad S, Robinson G. Survey of the Royal Australasian College of Physicians examination candidates: preparation and impact on lifestyle. Intern Med J 2005; 35:680-2.

17. Markus HR, Kitayama S. Culture and the self: implications for cognition, emotion, and motivation. Psychol Rev 1991; 98:224-53.

18. Karam E, Kypri K, Salamoun M. Alcohol use among college students: an international perspective. Curr Opin Psychiatry 2007; 20:213-21.

19. Folkman S, Lazarus RS. If it changes it must be a process: study of emotion and coping during three stages of a college examination. J Pers Soc Psychol 1985; 48:150-170.

20. Saipanish R. Stress among medical students in a Thai medical school. Med Teach 2003; 25:502-6. 